\title{
Voices of Women - perceptions of health, illness and health care service during pregnancy in Northwest Russia and Northern Norway in 2000
}

\section{A questionnaire study among Russian and Norwegian women}

\author{
Eli Heiberg*, Elisabet Helsing** and Svetlana Skurtveit* \\ * Norwegian Institute of Public Health, Oslo \\ ** National Board of Health, Oslo \\ Corresponding author: Eli Heiberg, E-mail: eli.heiberg@fhi.no
}

\begin{abstract}
Background: Norway has since 1994 supported health care directed towards breastfeeding and the wellbeing of mothers and babies during pregnancy and childbirth, and the immediate post-partum period in Northwest Russia. After five years of implementing the Baby Friendly Hospital Initiative (BFHI) 1994-1999 positive changes with increasing breastfeeding rates can be documented. While the BFHI concentrates on the immediate post-partum feeding routines for mother and baby, the project "Family Friendly Maternity Care" launched in autumn 1999 primarily focuses on routines attached to health and health care during pregnancy and childbirth.

Materials and methods: Women's own views on health and illness during pregnancy and the quality of health care received were recorded in a comparative survey in nine Russian and seven Norwegian maternity wards, all of them situated in the Barents region during spring 2000. A total of 764 women completed a questionnaire on the degree of satisfaction with the health care received and whether or not they felt personally taken care of or coldly and routinely treated at the antenatal consultations. The article concentrates on women's experience of health and illness during pregnancy, and their experience with the quality of the health care received.

Results: There were marked differences between the two groups concerning age and parity. The Russian women were younger with a mean age of 25 years, while the Norwegians had a mean age of 29 years. $65 \%$ of the Russian women gave birth to their first baby. Among the Norwegian women only $35 \%$ did so. More Russian women (36\%) reported suffering from a chronic disease of one kind or another as against $19 \%$ of the Norwegian women. Health before pregnancy was assessed as excellent or good by $76 \%$ of the Russians and $96 \%$ of the Norwegians. Both Norwegians and Russians reported a decline in perceived health during pregnancy, greatest however, among the Norwegians. Many of the Russians were admitted to hospital during pregnancy and stayed there for weeks in contrast to the Norwegian women who seldom stayed in hospital for more than a few days. Fear of premature birth was the most frequent reason given for hospital stay among the Russians. The results are discussed with reference to other health studies in the area and structural and cultural differences.
\end{abstract}

Conclusion: The survey reveals a need for intensified work towards a more dignifying and friendly maternity care.

Key words: pregnancy, self reported health, illness, health care, consumer satisfaction, breastfeeding, Northwest Russia, Northern Norway

\section{BACKGROUND}

The project "Family Friendly Maternity Care" funded by "The Barents Health Program in the Barents EuroArctic Region 1999-2002" has been part of the National Health Screening Service (SHUS) in Oslo, since 2002 part of Norwegian Institute of Public Health. SHUS was widely acknowledged for its expertise with different kinds of health surveys. As the project planned a comparative questionnaire study in both Northern Norway and Northwest Russia this institution was chosen as "home" base for the project.

The current project builds upon, and complements work that was initiated by the World Health Organization (WHO) introducing the Baby Friendly Hospital Initiative (BFHI) in Northwest Russia. The project has received financial support from Norway through the Barents Initiative. The BFHI concentrates on the immediate post-partum feeding routines for mother and baby, encourages opportunity for mother and baby to stay in intimate contact day and night, and for the mother to feed her baby on demand (1). These, and other changes in post-natal feeding routines, which by now are widely accepted in the region, were superimposed on an obstetric care system that in many ways have preserved what could be described as rather obsolete medical practices. The Russian antenatal care regimen is in general characterised by frequent, between 20 and 30, obligatory visits to different kinds of health specialists, most of them medical doctors. As in Norway the care is fragmented with little continuity. Many of the routine procedures are, however, similar. The 
future mothers keep their personal records, the Russian several pages long, compared with the Norwegian one sheet of paper record. This illustrates one of the major differences between the two countries, among which the number of visits and frequent hospital admissions during pregnancy may be the most striking. Minor complaints that in Norway most often are treated in policlinics, result in Northwest-Russia in long periods of hospitalisation (2).

There are written regulations "edicts" for every conceivable aspect of care, under the threat of possible reprimands or punishment. They may emanate either from central Government (Moscow) or locally. Fear of breaking the rules, and the fact that anything that is not explicitly permitted by rule, can be regarded as prohibited, may seem to make changing of practices in Russia a slow process. The isolation of the country in the period when many countries in Europe adopted a more family friendly and less interventionist approach to pregnancy and birth (3), makes Russian maternity wards in the year 2000 appear strangely old fashioned. Many wards did not allow family members to accompany the woman during birth, or to visit her and the baby at the post-partum ward.

In 1999 the emphasis of the project was broadened to include a more family friendly obstetric care in general, in accordance with the WHO guidelines for care during normal pregnancies and birth (4). Various groups of health professionals from different parts of the region have been enabled to attend national and international conferences, workshops and seminars focusing on modern, evidence based care during birth, post-partum and breastfeeding. In the spring of 2000 a questionnaire survey "Voices of Women in the Barents Region" (VOW 2000) concerning women's perception of the health care they received during these periods was conducted in nine Russian and seven Norwegian hospitals. The study has functioned as a "baseline" and a guide for implementation of the main activities within the project.

For this article we have selected topics from the survey that might highlight differences between Russian and Norwegian women concerning:

- Perceived own health status before pregnancy and during pregnancy

- Specific illness and/or disease experienced during pregnancy

- Reasons for, and duration of hospital stay during pregnancy

- Degree of satisfaction with the health care received during the antenatal period.

\section{MATERIALS AND METHODS}

\section{Questionnaires}

The questions were partly drawn from a databank of questions "The Women's Experience of Birth (WEB)" $(2,5)$. These questions, originally made for oral inter- views, had to be adjusted for self-reporting. Additional questions were drawn from a Norwegian survey of pregnancy and work (6). The questionnaire had in total 105 questions concerning the most recent pregnancy, birth and breastfeeding in the immediate post-partum period.

The questionnaire was translated into Samii and compared with the Norwegian and English version. The Norwegian and English versions were translated into Russian by two independent Russian interpreters and translations compared. A pilot study was undertaken among twenty Norwegian women in one of the participating wards.

\section{Distribution and collection of questionnaires}

It had been planned to hand out the questionnaire to every woman who had given birth to a live child while she still was in the post-partum ward. It had, however, to be left to the chief midwife or doctor in the ward to judge whether the women were in a condition fit to respond. Severe illness of either mother or baby, discharge immediately after birth, or language difficulties might render it impossible or unethical to hand out a questionnaire. The data collection period was 9. March to mid May 2000 in both countries. Some differences in distribution and collection of questionnaires within the period were:

\section{Russia}

In Russia 9 maternity wards ${ }^{1}$ participated in the survey and a total of 382 women completed the questionnaire. The distribution of the questionnaires was entrusted to the Hospital Directors of each hospital who had been given a total of 430 questionnaires. According to the responsible persons almost every woman giving birth in each ward was given the questionnaire. If the total number of women invited is taken to be 430 , this gives a response rate of $89 \%$. Five women $(1.3 \%)$ returned the questionnaire unanswered.

\section{Norway}

In Norway 7 maternity wards ${ }^{2}$ participated. One or two midwives in each ward were responsible for the distribution and collection of questionnaires. During the collection period 625 births were registered in these wards. About 55 (9\% of the total) women left the ward before they got a questionnaire. $35(6 \%)$ of the women returned the questionnaire unanswered. In total 382 women completed the questionnaire. If it is assumed that all of the 625 women giving birth in the seven

\footnotetext{
${ }^{1}$ Maternity hospital no 1 and 2 in Murmansk and the hospitals in Kandalaksha and Olenegorsk participated from the Murmansk Region. From the Archangelsk Region the hospital in Severodvinsk, Regional hospital, Samoilova hospital and City hospital no. 7 in Archangelsk, and the hospital in Naryan-Mar in Nenets Autonomous District participated.

${ }^{2}$ Maternity home, Alta, Maternity home, Midt-Troms, Finnsnes, Hammerfest hospital, Hålogaland hospital, Harstad, Kirkenes hospital, Sonjatun Maternity home Storslett, and University hospital Northern Norway, Tromsø.
} 
maternity wards were invited to take part in the survey, the response rate was $61 \%$. All the wards were asked to record why women did not participate in the survey. Only one hospital (Tromsø) did this in a systematic way. During the data collection period women in Tromsø gave birth to 305 babies. 188 women (62\%) returned the questionnaire and $22(7 \%)$ returned it unanswered. The hospital reported that $12(4 \%)$ of the women were not given the questionnaire because of illness in either mother or baby, and six (3\%) because of language difficulties. At the time when the survey was done, women were normally given the opportunity to leave the ward the same day or the day following birth. In Tromsø 29 women (10\%) did this.

\section{Consent, confidentiality and compliance}

To ensure privacy of the women each questionnaire was handed out in an envelope that the woman could seal before returning the questionnaire to the ward. An enclosed letter explained the purpose of the study, ensuring that anonymity and confidentiality were guaranteed, and that returning the questionnaires unanswered would not entail any reprisals.

\section{Analysis}

Statistical analyses were performed with SPSS 10.0 for Windows. Differences were tested by the Chi-square test. Level of significance was set to $\mathrm{p}<0.05$.

\section{RESULTS}

A total of 764 women, 382 women from each country, answered all or most of the questions. The number of answers to each question is given in the tables and is the basis for the calculated frequencies.

Socio-demographic data about the Russian and Norwegian women are shown in Table 1 . Almost $80 \%$ of the Russian women were below 30 years of age, against about $50 \%$ of the Norwegians $(p<0.001)$. There were almost twice as many primi-parae in the Russian sample $(\mathrm{p}<0.001)$.

The highest education bracket contained $22 \%$ of the Norwegian mothers against $10 \%$ of the Russians $(p<0.001)$. A significant difference with regard to participation in the work force in the latter half of pregnancy can also be seen $(p<0.001)$.
Table 1. Socio-demographic characteristics of the Russian and Norwegian women participating in the survey.

\begin{tabular}{lcc}
\hline & Russian (\%) & Norwegian (\%) \\
\hline Age (years) & & \\
$15-19$ & $40(10.6)$ & $12(3.2)$ \\
$20-29$ & $256(67.9)$ & $181(47.6)$ \\
$30-39$ & $74(19.6)$ & $180(47.4)$ \\
$40+$ & $7(1.9)$ & $7(1.8)$ \\
Total answering this question & $377(100)$ & $380(100)$ \\
Parity & & \\
$\quad$ primi & $236(65.2)$ & $135(35.4)$ \\
multi & $126(34.8)$ & $246(64.6)$ \\
Total answering this question & $362(100)$ & $381(100)$ \\
Education (years) & & \\
$5-9$ & $30(8.0)$ & $20(5.3)$ \\
$10-12$ & $165(43.8)$ & $124(32.6)$ \\
$13-16$ & $144(38.2)$ & $150(39.5)$ \\
$16+$ & $38(10.1)$ & $86(22.6)$ \\
Total answering this question & $377(100)$ & $380(100)$ \\
Work in the latter half of pregnancy & & \\
$\quad$ yes & $202(55.6)$ & $308(81.3)$ \\
Total answering this question & $363(100)$ & $379(100)$ \\
\hline
\end{tabular}

Concerning type of work according to physical demands there were no great differences (data not shown). The majority of both Russian and Norwegian women have jobs where they stand and walk more than half of their working day. The length of the working week was, however, higher for the Norwegian women. Among those having a paid job $48 \%$ of the Norwegians and $21 \%$ of the Russians worked full time (working hours between 37-40 hours per week). The degree of individual control differed. One in four of the Russian women, compared to one in five of the Norwegians, reported that they seldom or never could decide their own work pace.

Table 2 shows how the women replied to the fivestep scale on perception of own health before and during pregnancy. Only $12 \%$ of the Russian women rated their health as excellent before pregnancy. However, $64 \%$ assessed it as good. Among the Norwegian women, $54 \%$ assessed their health as excellent and $42 \%$ as good before pregnancy. It may be noted that twice as many Russians as Norwegians seem to be unable or unwilling to classify their health, replying "neither good nor bad". Both Russian and Norwegian

Table 2. Self reported health before and during pregnancy among Russian and Norwegian women.

\begin{tabular}{lccccc}
\hline & \multicolumn{2}{c}{ Before pregnancy } & & \multicolumn{2}{c}{ During pregnancy } \\
\cline { 2 - 3 } \cline { 5 - 6 } & Russian (\%) & Norwegian (\%) & & Russian (\%) & Norwegian (\%) \\
\hline Excellent & $43(11.5)$ & $205(53.7)$ & & $32(8.5)$ & $92(24.3)$ \\
Good & $239(63.7)$ & $160(41.9)$ & & $197(52.3)$ & $148(39.2)$ \\
Neither good nor bad & $60(16.0)$ & $13(3.4)$ & & $129(34.2)$ & $75(19.8)$ \\
Not so good & $31(8.3)$ & $3(0.8)$ & & $3(0.8)$ & $52(13.8)$ \\
Poor & $2(0.5)$ & $1(0.3)$ & & $16(4.2)$ & $11(2.9)$ \\
Total answering this question & $375(100)$ & $382(100)$ & & $377(100)$ & $378(100)$ \\
\hline
\end{tabular}


women report a decline in perceived health during pregnancy, greatest however, among the Norwegian women. Split into age groups these differences persist (data not shown).

Fig. 1 shows the kind of long lasting or chronic illness among Russian and Norwegian women during pregnancy. Among the Russian women 36\% reported suffering from a chronic disease of one kind or another as against $19 \%$ of the Norwegian women. It is interesting to note that while the Russian women struggle with intestinal problems, renal disease and high blood pressure, the Norwegians most often reported allergic conditions such as asthma and eczema, and musculoskeletal complaints. Among "other" illnesses Russian women reported anaemia, chronic sinusitis, varicose veins and myopia or short-sightedness, while the Norwegian women reported headache, psoriasis and disorders of metabolism. On average, the Russian women gave more multiple answers than did the Norwegians to the question on illness.

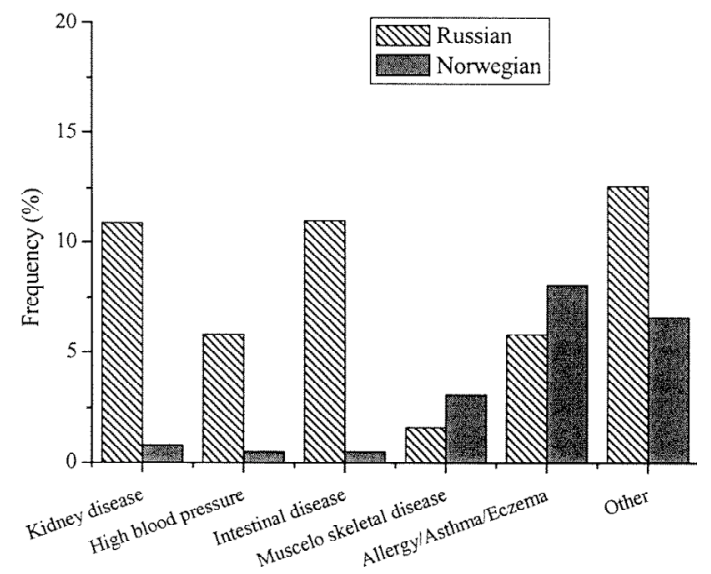

Figure 1. Frequencies and kind of long lasting or chronic illness reported among Russian and Norwegian women that attended the study. Frequencies (\%) were calculated from the total number of Russian $(\mathrm{n}=382)$ and Norwegian women $(n=382)$.
A major difference between the group of Russian and Norwegian women is the admission to hospital while pregnant. Almost every woman (Russian $\mathrm{N}=372$, Norwegian $\mathrm{N}=378$ ) answered the question on admittance to hospital during pregnancy. Of the Russian women, $55 \%$ as against $16 \%$ of the Norwegians reported having been admitted to hospital $(p<0.001)$. Fig. 2a shows that among Norwegian women admitted to hospital $78 \%$ stayed in hospital only once. On the contrary, $22 \%$ of the Russian women were admitted to hospital more than twice during their pregnancy.

Fig. $2 b$ shows that the length of stay in hospital during pregnancy also varied considerably. Among those admitted to hospital, the majority of the Russians reported a hospital stay of 14 days or more as against 1-6 days among the majority of the Norwegians.

Table 3 shows that fear of premature birth was the most frequent reason for hospital admission among the Russian women, whereas for Norwegian women it was high blood pressure. This question had a list of possible reasons, many of which were reciprocally related. Many women marked several reasons.

Table 3. Reasons given for stay in hospital during pregnancy.

\begin{tabular}{lcc}
\hline & Russian (\%) & Norwegian (\%) \\
\hline Fear of premature birth & $128(62.4)$ & $10(16.9)$ \\
High blood pressure & $55(26.8)$ & $24(40.7)$ \\
Swelling & $55(26.8)$ & $12(20.3)$ \\
Bleeding & $13(6.3)$ & $5(8.5)$ \\
Poor growth of the baby & $18(8.8)$ & $2(3.4)$ \\
Emesis & $22(10.7)$ & $2(3.4)$ \\
Other reasons & $48(23.4)$ & $27(45.8)$ \\
Number of women staying & & \\
in hospital during pregnancy & 205 & 59 \\
\hline
\end{tabular}

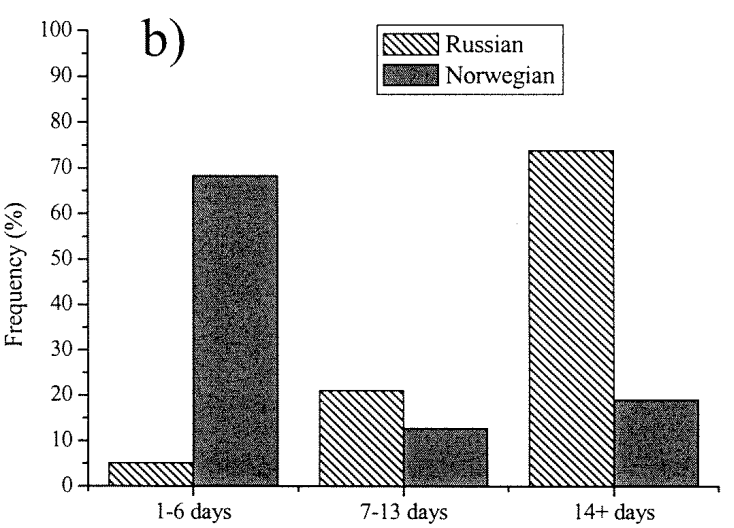

Figure 2. a) Number of admissions to hospital during pregnancy among Russian and Norwegian women. b) Length of stay in hospital during pregnancy among Russian and Norwegian women. Frequencies (\%) were calculated from the number of women having been admitted to hospital of the Russian $(n=205)$ and of the Norwegian $(n=59)$ women. 
There was a striking difference in the number of gynaecological examinations performed during pregnancy (Fig. 3). The Russian women experienced several times the number of this procedure than do Norwegian women. While the majority of Norwegian women had one, maximum two gynaecological examinations during pregnancy, quite a few Russian women (14\%) reported between nine and twenty examinations, some even more $(\mathrm{p}<0.001)$.

Table 4 shows how the women replied to a fivestep scale concerning degree of satisfaction with the health care received during pregnancy. The Norwegian mothers in general were more positive and unequivocal about the care they had received than the Russians. Of the latter $11 \%$ rated the health care service as excellent, compared to $49 \%$ of the Norwegians. Variables such as age, parity and education, perceptions of own health status, duration of hospital stay in pregnancy, frequency of gynaecological examinations, were not significantly related to the degree of satisfaction (data not shown). A relatively high number, all together $22 \%$ of the Russian mothers chose not to voice an opinion (neither good nor bad).

In addition to the degree of satisfaction with the health care received, the questionnaire also comprised questions concerning degree of trust and dignity, e.g. if the woman felt she was respected as an individual, if she felt secure, if she was treated coldly etc. at the antenatal consultations. Table 5 shows the answers to some of these questions. Questions of this kind proved apparently a bit difficult to answer for the Russian women. Norwegian women more often reported being more personally taken care of, their wishes being more often asked for and respected. As shown in Table 5 the response rate on questions among Russian and Norwegian women to this question differed widely. In spite of the uncertainties connected with a low response rate we chose, however, to present these data to indicate a need for a changed attitude towards pregnant Russian women.

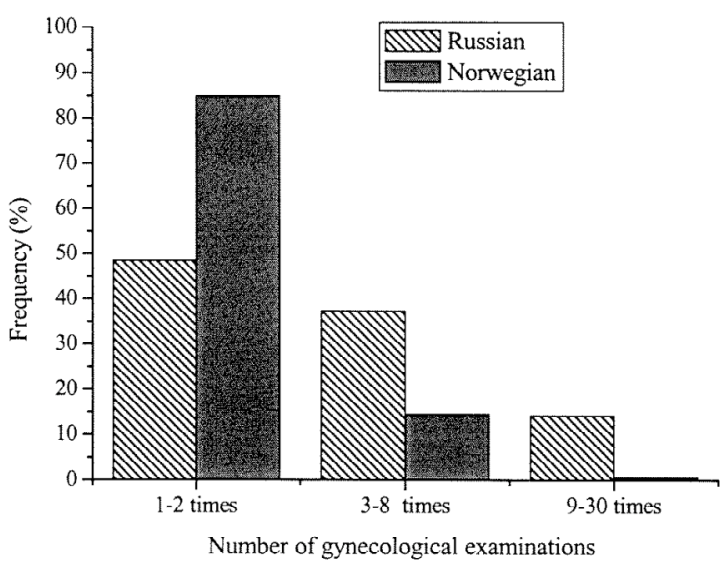

Figure 3. Number of gynaecological examinations during pregnancy. Frequencies (\%) were calculated from the number of women having experienced this examination and answered this question of the Russian $(\mathrm{n}=268)$, and of the Norwegian $(n=325)$ women.
4. Degree of satisfaction with the health care service received during pregnancy.

\begin{tabular}{lcc}
\hline & Russian (\%) & Norwegian (\%) \\
\hline Excellent & $41(11.0)$ & $186(49.3)$ \\
Good & $178(47.8)$ & $163(43.2)$ \\
Neither good nor bad & $83(22.3)$ & $22(5.8)$ \\
Not so good & $65(17.5)$ & $5(1.3)$ \\
Poor & $5(1.3)$ & $1(0.3)$ \\
Total answering this & & \\
question & $372(100)$ & $377(100)$ \\
\hline
\end{tabular}

Table 5. Feelings during antenatal consultations.

\begin{tabular}{|c|c|c|}
\hline & Russian (\%) & Norwegian $(\%)$ \\
\hline \multicolumn{3}{|l|}{ Respected } \\
\hline yes & $147(57.0)$ & $350(95.9)$ \\
\hline no & $22(8.5)$ & $5(1.4)$ \\
\hline do not know & $89(34.5)$ & $10(2.7)$ \\
\hline Total answering this question & $258(100)$ & $365(100)$ \\
\hline \multicolumn{3}{|l|}{ Welcome } \\
\hline yes & $149(60.8)$ & $363(97.1)$ \\
\hline no & $32(13.1)$ & $4(1.1)$ \\
\hline do not know & $64(26.1)$ & $7(1.9)$ \\
\hline Total answering this question & $245(100)$ & $374(100)$ \\
\hline \multicolumn{3}{|l|}{ Personally taken care of } \\
\hline yes & $139(58.6)$ & $327(88.6)$ \\
\hline no & $60(25.3)$ & $21(5.7)$ \\
\hline do not know & $38(16.0)$ & $21(5.7)$ \\
\hline Total answering this question & $237(100)$ & $369(100)$ \\
\hline \multicolumn{3}{|l|}{ Secure } \\
\hline yes & $149(61.3)$ & $337(91.6)$ \\
\hline no & $59(24.3)$ & $10(2.7)$ \\
\hline do not know & $35(14.4)$ & $21(5.7)$ \\
\hline Total answering this question & $243(100)$ & $368(100)$ \\
\hline \multicolumn{3}{|l|}{ Coldly and routinely cared for } \\
\hline yes & $51(23.0)$ & $23(6.5)$ \\
\hline no & $142(64.0)$ & $320(90.4)$ \\
\hline do not know & $29(13.1)$ & $11(3.1)$ \\
\hline Total answering this question & $222(100)$ & $354(100)$ \\
\hline \multicolumn{3}{|l|}{ My wishes were asked for } \\
\hline yes & $113(52.1)$ & $275(76.0)$ \\
\hline no & $44(20.3)$ & $48(13.3)$ \\
\hline do not know & $60(27.6)$ & $39(10.8)$ \\
\hline Total answering this question & $217(100)$ & $362(100)$ \\
\hline \multicolumn{3}{|l|}{ My wishes were respected } \\
\hline yes & $100(47.4)$ & $300(83.1)$ \\
\hline no & $36(17.1)$ & $22(6.1)$ \\
\hline do not know & $75(35.5)$ & $39(10.8)$ \\
\hline Total answering this question & $211(100)$ & $361(100)$ \\
\hline
\end{tabular}




\section{DisCUSSION}

The most important findings in this study revolve around differences in perceived and diagnosed health and illness in Russian and Norwegian pregnant women. The Russian women reported not only more, but also more severe illnesses and diseases than the Norwegian women. They were also more frequently admitted to hospital during pregnancy, and eight times as many Russian women as Norwegian stayed in hospital for more than two weeks. The Russians also felt less respected, their opinion and wishes being seldom asked for.

Our data rely solely on women's self-evaluation. The validity of self-evaluation has in many studies proved to be realistic. In particular self-evaluation of health status has been found to show a substantial stability through time (7). Participation rate was higher for Russian women than for Norwegian women and we have no information about the women who did not participate. However, we have learned that only $4 \%$ of the women giving birth in the hospital in Tromsø did not participate because of illness in either mother or baby. Another problem of our study, is the relatively small cohort size. Thus, some results may only be indicative of the situation.

The differences between the experience of Russian and Norwegian women have probably many levels of explanation. There are different structures of organisation of the health care system and antenatal procedures in the two countries. Furthermore, the economical situation differs and the "threshold of tolerance" emanating from these differences will vary, both in mothers and in health workers in ways that our data do not reveal.

Within the Russian system antenatal care is predominantly provided by medical doctors, who in their training have been taught to focus on possible deterioration of health, illness and disease. Between 20 and 30 antenatal check-ups are prescribed in the form of written regulatory edicts, and penalty systems may be employed vis-à-vis mothers and doctors who fail to comply. On the contrary, Norwegian women have a maximum of 10-14 antenatal consultations, most of them with midwives. Norwegian midwives collaborate with doctors, as a team they are responsible for the care and service given. The healthy and caring aspects of childbearing might thus be more in focus in the Norwegian than in the Russian system.

Illnesses that in Norway are treated in outpatient clinics are in Russia treated in hospital. Two thirds of the Russian women admitted to hospital, stayed there for a considerable length of time during pregnancy, delivery not included. This possible overuse of hospitalisation reflects a tendency towards medicalisation within the system of health care in Russia and perhaps also a need to play safe in a rigid system with prescriptions for every aspect of care.

According to our small size sample Russian women report to suffer not only more, but also more severe illnesses, before and during pregnancy than do Norwegian women. Renal disease and intestinal problems were commonly reported among Russian women. Among the Norwegians, in contrast, allergy, asthma and/or eczema were experienced as the most frequent. The finding that asthma and allergies are lower in Russia than in Norway is supported by a self-reporting questionnaire health study from the Archangelsk region by Nilssen et al (8). Smith-Sivertsen (9) in an interview study, however, in a comparison between women (not pregnant) in Nikel/Zapolyarny and SørVaranger, found that different respiratory problems were more frequently reported among Russians. The Nikel/Zapolyarny area is known as a heavily polluted area.

The findings in various studies (8-9) concerning chronic illnesses among Russians, compared with Norwegians in the Barents region, show somewhat inconsistent results. Hansen and Tønnesen (10) showed in an interview study great improvement of health in a five years' perspective (1992-1997) among the population of the Kola Peninsula. They found "few drastic differences between the Kola Peninsula and Norway as far as the younger and middle aged groups are concerned". Concerning the status of health and illness in the VOW 2000 study the women were asked to rate their health status before and during pregnancy on a five graded scale from excellent to poor. Excellent/good health was reported by 76 and $96 \%$, respectively, the Norwegians the highest. In contrast, the Archangelsk study (8), using a four graded scale from very good to poor, showed that only $44 \%$ of women in a corresponding age group (20-29), but not pregnant, rated their health as good or very good.

In the VOW 2000 study many symptoms were reported solely by the Russians, this could be myopia or short-sightedness, astigmatism, sinusitis, and varicose veins. Hansen and Tønnesen (10) point out that mentioning of symptoms might be connected either to cultural and/or linguistic differences. The term illness (bolezn) may be interpreted differently, and also that there are cultural differences as to what is considered to be an illness. In accordance with arguments along this line one may say that medicalisation have become part of a cultural tradition and as such widely accepted among both the public and the health care system. Bearing the good health status before pregnancy in mind, and the very slight decline in health reported during pregnancy, the listing of diagnoses suffered in pregnancy thus may reflect a tendency embedded in the culture towards overstating pathological conditions. Furthermore, the most frequent reason reported for staying in hospital among the Russians was fear of premature birth, a term which is vaguely defined and strongly influenced by subjective opinions and feelings of anxiety.

Concerning the degree of satisfaction with the health care received during antenatal consultations there were significant differences among Russian and 
Norwegian women in the answers. The Norwegians felt much more personally respected and taken care of than did the Russians. This finding is perhaps the strongest argument for a continuation of the work towards a more family friendly approach in the Russian health care system for childbearing. A followup study conducted in the same Russian hospitals in 2002 will hopefully show the impact of this work and most important improvement in the conditions offered childbearing women in Russia.

\section{ACKNOWLEDGEMENTS}

We thank Dr. Beverley Chalmers, University of Toronto for her contribution concerning the Voices of Women questionnaire. We also express our gratitude to Dr. Tatyana J. Dinekina, Maternity Hospital no. 3 Murmansk, Dr. Nina I. Kondakova, Northern State University Archangelsk and Dr. Vyacheslav Kabakov, Health Care Department, Archangelsk Region for their assistance in conducting the survey.

\section{REFERENCES}

1. Helsing E, Chalmers BE, Dinekina TJ, Kondakova NI. Breastfeeding, baby friendliness and birth in transition in North Western Russia: a study of women's perceptions of the care they receive when giving birth in six maternity homes in the cities of Archangelsk and Murmansk, 1999. Acta Pcediatr 2002; 91: 578-83.

2. Chalmers B, Muggah H, Samarskaya MF, Tkatchenko E. Women's experience of birth in St. Petersburg, Russian Federation, following a maternal-child health programme. Birth 1998; 25: 107-16.

3. Enkin M, Keirse M, Neilson J, Crowther C, et al. A guide to effective care in pregnancy and childbirth. Oxford: Oxford University Press, 2000.

4. WHO - Care in Normal Birth: a practical guide. Maternal and newborn health/safe motherhood unit. Family and reproductive health. Geneva: World Health Organization, 1996.

5. Chalmers B. Black women's birth experience: Changing traditions. J Psychosom Obstet Gynecol 1987; 6: 21124.

6. Wergeland E, Strand K, Endresen EH. "Pregnant in Norway at the entrance of the nineties" a national survey Norway 1989 (in Norwegian). Oslo: Institutt for forebyggende medisin, Universitetet i Oslo. Report no. 1, 1991.

7. Fylkesnes K. Factors affecting self-evaluated general health status - and the use of professional health care services. Doctoral thesis, Tromsø: University of Tromsø, 1991.

8. Nilssen O, Kalinin A, Brenn T, et al. Helseundersøkelsen i Arkhangelsk 2000. Tromsø and Arkhangelsk: Institutt for samfunnsmedisin, Universitetet i Tromsø and Northern State Medical University, Arkhangelsk. Report no. 66, 2003.

9. Smith-Sivertsen T. Air pollution and health in the Norwegian-Russian border area. Tromsø Institute of Community Medicine, Tromsø University. Report no. 55, 2000.

10. Hansen E, Tønnesen A. Environment and living conditions on the Kola Peninsula. Oslo: Fafo Institute for Applied Social Science. Report no. 260, 1998. 